\title{
Virucidal Action Mechanism of Alcohol and Divalent Cations Against Human Adenovirus
}

\author{
Natalia Martín-González ${ }^{1 \dagger}$, Leonam Vieira Gonçalves ${ }^{2 \dagger}$, Gabriela N. Condezo ${ }^{3}$, \\ Carmen San Martín ${ }^{3}$, María Rubiano ${ }^{2}$, Ian Fallis ${ }^{4}$, Joseph R. Rubino ${ }^{5}$, M. Khalid ljaz ${ }^{5}$, \\ Jean-Yves Maillard ${ }^{2 *}$ and Pedro J. De Pablo ${ }^{1 *}$ \\ ${ }^{1}$ Department of Condensed Matter Physics, Universidad Autónoma de Madrid, Madrid, Spain, ${ }^{2}$ School of Pharmacy and \\ Pharmaceutical Sciences, Cardiff University, Cardiff, Wales, United Kingdom, ${ }^{3}$ Department of Macromolecular Structures, \\ Centro Nacional de Biotecnología-Consejo Superior de Investigaciones Cientificas, Madrid, Spain, ${ }^{4}$ School of Chemistry, \\ Cardiff University, Cardiff, United Kingdom, ${ }^{5}$ Center of Innovation, Reckitt Benckiser Inc., Montvale, NJ, United States
}

Hygiene and disinfection practices play an important role at preventing spread of viral infections in household, industrial and clinical settings. Although formulations based on $>70 \%$ ethanol are virucidal, there is a currently a need to reformulate products with much lower alcohol concentrations. It has been reported that zinc can increase the virucidal activity of alcohols, although the reasons for such potentiation is unclear. One approach in developing virucidal formulations is to understand the mechanisms of action of active ingredients and formulation excipients. Here, we investigated the virucidal activity of alcohol $(40 \% \mathrm{w} / \mathrm{v})$ and zinc sulfate $(0.1 \% \mathrm{w} / \mathrm{v})$ combinations and their impact on a human adenovirus (HAdV) using, nucleic acid integrity assays, atomic force microscopy (AFM) and transmission electron microscopy (TEM). We observed no difference in virucidal activity $\left(5 \log _{10}\right.$ reduction in $60 \mathrm{~min}$ ) against between an ethanol only based formulation and a formulation combining ethanol and zinc salt. Furthermore, TEM imaging showed that the ethanol only formulation produced gross capsid damage, whilst zinc-based formulation or formulation combining both ethanol and zinc did not affect HAdV DNA. Unexpectedly, the addition of nickel salt $\left(5 \mathrm{mM} \mathrm{NiCl}_{2}\right)$ to the ethanol-zinc formulation contributed to a weakening of the capsid and alteration of the capsid mechanics exemplified by AFM imaging, together with structural capsid damage. The addition of zinc sulfate to the ethanol formulation did not add the formulation efficacy, but the unexpected mechanistic synergy between $\mathrm{NiCl}_{2}$ and the ethanol formulation opens an interesting perspective for the possible potentiation of an alcohol-based formulation. Furthermore, we show that AFM can be an important tool for understanding the mechanistic impact of virucidal formulation.

Keywords: virus damage, biocides, virus mechanics, AFM, adenovirus

\section{INTRODUCTION}

Understanding the mode of action of a biocidal products has been shown to be relevant for establishing scientific principles, improvement of biocidal products as well as usage optimization, and combatting emerging resistance by target microorganism (Myers, 2008; Condell et al., 2012). Biocides are multi-target antimicrobial agents with broad spectrum of action. Understanding 
their interactions with microbial targets, here viruses, informs our knowledge of mechanisms contributing to viral inactivation or viral resistance mechanisms, and contributes to improving efficacy through formulation design and better usage recommendation of the product in practice (Russell, 2003). Nonenveloped viruses offer less targets for virucidal action compared to enveloped ones. These targets comprise mainly the capsid, viral encoded receptor binding proteins and viral genomes (Maillard, 2001; Myers, 2008). The mechanisms of virucidal action against non-enveloped viruses remain poorly studied.

The increased use of alcohols over other antimicrobials can be attributed to their rapid and broad-spectrum antimicrobial activity against bacteria, viruses and fungi (Mcdonnell and Russell, 1999; Guthery et al., 2005). Alcohols show substantial virucidal activity against enveloped viruses as compared to nonenveloped ones, which suggests that the viral lipid envelope is a potential target (van Engelenburg et al., 2002). Alcohol in concentrations between 59 and 90\% (w/v) show a fast acting and broad-spectrum of antimicrobial action (Mcdonnell and Russell, 1999; Macinga et al., 2008; Alhmidi et al., 2017), but persistence of efficacy is relatively low as alcohols evaporate quickly, and their residual activity after short periods of time is thus compromised (Rutala and Weber, 2014; Alhmidi et al., 2017). Moreover, usage of $60-90 \%$ (w/v) alcohol in surface and hand disinfectants can be problematic mostly due to increased flammability, toxicity and generation of high amounts of volatile organic compounds (VOCs) affecting user safety (Kramer et al., 2006). VOCs generated by household products containing aforementioned alcohol concentrations may have short and longterm adverse health effects on animal and human in indoor environments including sensory irritation, allergies, asthma and leukemia (Suchomel et al., 2009). The design of formulations that accommodate a decrease in alcohol concentration while retaining an appropriate virucidal activity is thus essential. Alcohols in synergistic combination with other antimicrobials (e.g., metals) are being studied not only to address those issues but to confer higher efficacy and persistence to a biocidal product as well (Gaonkar et al., 2006). The usage of zinc salts and oxides as antimicrobial agents is still limited. The main usage of zinc is as preservative in combination with other active ingredients in biocidal products used as pesticide in agriculture (Rajasekaran et al., 2016), as hand and skin antisepsis in household and healthcare products (Guthery et al., 2005; Gonçalves et al., 2012), and as antifouling agent in paints for metal surface treatment (Ytreberg et al., 2010). The combination of alcohol and zinc salts has not been widely reported, but the use of zinc pyrithione has shown some benefit on formulation antimicrobial activity and persistence (Guthery et al., 2005). Usage of other zinc salts such as zinc sulfate (as used in the present study) in combination with alcohol has not been reported commercially or academically yet.

In this context, the main goal of this study was to analyse the capacity of ethanol/zinc salt combination to present virucidal activity against non-enveloped viruses with identification of possible targets leading to a better understanding of the mechanism(s) of action. The influence of such combination against mammalian virus (adenovirus) capsid susceptibility to mechanical stress and virus integrity was verified through a novel nanoindentation analysis by Atomic Force Microscopy (AFM). Furthermore, virucidal efficacy testing alongside viral purification and subsequent DNA extraction after exposure to formulations was performed in order to elucidate whether viral nucleic acid is a potential target for the formulation system under study.

Overall, this study sought to confirm the potentiation of the virucidal activity of formulated ethanol with divalent cations, and to understand the mechanisms of action for such activity against human adenovirus.

\section{MATERIALS AND METHODS}

\section{Formulations}

The formulations tested where obtained from Reckitt Benckiser and their basic composition are described in Table 1. Excipients (non-active ingredients) are not disclosed due to proprietary issues. The virucidal efficacy of unformulated biocides are most commonly studied, and investigation of formulation is rarely reported in the literature. This study looked at the effect of the formulation (RB-Full) and controls consisted of formulated ethanol (RB-ethanol) and zinc (RB-zinc).

\section{Propagation and Purification of Human Adenovirus Type 2 and 5}

The human adenovirus type 5 variant FC31-attP (HAdV5/attP) was used for the AFM and TEM investigations. HAdV5/attP is structurally similar to the wild type human adenovirus type 5, but its genome contains some deletions for genes involved in replicative cycle control (E1 region) and host immune system evasion (E3 region) (Alba et al., 2007). It also expresses green fluorescent protein (GFP) to facilitate tracking of virus amplification kinetics and titration. The wild type human adenovirus type 2 (HAdV2) is used in virucidal standard efficacy tests.

HAdV5/attP and HAdV2 were propagated in HEK293 and HeLA cells, respectively. Infected cells were harvested $36 \mathrm{~h}$ (HAdV5/attP) or 3 days (HAdV2) post-infection and viral particles were purified by ultracentrifugation in cesium chloride (CsCl) gradients (Condezo et al., 2015), after centrifugation of the freeze-thaw disrupted cells to remove cell debris. TD1X Buffer ( $137 \mathrm{mM} \mathrm{NaCl}, 5.1 \mathrm{mM} \mathrm{KCl}$, $0.7 \mathrm{mM} \mathrm{Na} 2 . \mathrm{HPO}_{4} .7 \mathrm{H}_{2} \mathrm{O}$ and $25 \mathrm{mM}$ Tris base at $\mathrm{pH} 7.4$ ) was used to prepare $\mathrm{CsCl}$ gradients. Ultracentrifugation was conducted at $219,000 \mathrm{~g}$ (LE-80K Ultracentrifuge, Beckman Coulter) for $90 \mathrm{~min}$ at $18^{\circ} \mathrm{C}$ in 1.25 and $1.40 \mathrm{~g} / \mathrm{ml} \mathrm{CsCl}$

TABLE 1 | Formulations studied and their composition.

\begin{tabular}{ll} 
Formulation & Composition \\
\hline RB-Full & $40 \%(\mathrm{w} / \mathrm{v})$ ethanol $+0.1 \%(\mathrm{w} / \mathrm{v})$ zinc sulfate + excipients; $\mathrm{pH} 10.5$ \\
RB-Ethanol & $40 \%(\mathrm{w} / \mathrm{v})$ ethanol + excipients; $\mathrm{pH} 10.5$ \\
RB-Zinc & $0.1 \%(\mathrm{w} / \mathrm{v})$ zinc sulfate + excipients; $\mathrm{pH} 10.5$ \\
RB-Control & Excipients; $\mathrm{pH} 10.5$
\end{tabular}


step gradient. Following a first centrifugation step, viral bands were extracted, deposited in a tube containing $1.31 \mathrm{~g}$ $\mathrm{mL}^{-1} \mathrm{CsCl}$ and centrifuged at $219,000 \mathrm{~g}$ for $18 \mathrm{~h}$ to form a continuous gradient. Virus particles extracted from the gradient were desalted through column chromatography (BioRad 10 DC, UK), eluted with HBS (20 mM Hepes, $150 \mathrm{mM}$ $\mathrm{NaCl}, \mathrm{pH} 7.8$ ) and stored in aliquots with $10 \%$ glycerol at $-80^{\circ} \mathrm{C}$.

HAdV2 infectious concentration was quantified using the Spearman-Kaeber method 6 and 7 days post-infection (19) and concentration expressed as $\mathrm{PFU} \mathrm{ml^{-1 }}$. HAdV5/attP was quantified by spectrophotometry (Hitachi Model F-2500 FL) using the hexon fluorescence emission spectra. Briefly, $0.15 \mathrm{~mL}$ samples of diluted viral preparations in sealed quartz cuvettes were excited at $285 \mathrm{~nm}$, and emission spectra were measured from 310 to $375 \mathrm{~nm}$ using excitation and emission slit widths of $10 \mathrm{~nm}$. The spectra were corrected by subtraction of the buffer spectrum. The maximum emission intensity for each spectrum was found at $333 \mathrm{~nm}$ and recorded. The concentration expressed as viral particles $\mathrm{mL}^{-1}$ was determined from a calibration curve calculated from a virus preparation with a known concentration.

\section{Determination of Virucidal Activity}

The BS EN 14476 quantitative virucidal suspension test (BS EN 14476:2013+A2, 2019) in clean condition, i.e., with sterile hard water as the only interfering substance and without organic load, was carried out against HAdV2. Briefly, $500 \mu \mathrm{l}$ of test viruses were prepared by adding $340 \mu \mathrm{l}$ of HAdV2 stock suspension $\left(10^{9}\right.$ $\mathrm{PFU} / \mathrm{ml}$ ) to $160 \mu \mathrm{l}$ of distilled water. One hundred mocroliter of the test HAdV2 was then added to $900 \mu \mathrm{l}$ of formulation. After $60 \mathrm{~min}, 100 \mu \mathrm{l}$ of test viral suspension was added to a Microspin S-200 HR size-exclusion chromatography column (GE, UK) to quench the activity of the formulation activity and to reduce host cell cytotoxicity. Then, $100 \mu \mathrm{l}$ of the mixture were serially diluted in $900 \mu \mathrm{l}$ purified water (1:10 serial dilutions). Each dilution (100 $\mu \mathrm{l}$ ) was added to wells of 24 tissue culture plates containing with $70-80 \%$ confluence HeLa cells monolayer. The infective virus concentration was determined by Spearman-Kaeber method, 6 and 7 days post-infection (Flint and American Society for Microbiology, 2009). Reduction in infectivity is expressed as $\mathrm{PFU} / \mathrm{ml}$ which relate to the number of infectious particles.

\section{Viral DNA Extraction, Quantification, Analysis of DNA Damage}

The DNA analysis post viral treatment method described in Maillard et al. (1995) was adapted for HAdV2. Twenty microliter of purified HAdV2suspension $\left(10^{9} \mathrm{PFU} / \mathrm{ml}\right)$ was added to 80 $\mu \mathrm{l}$ of each formulation for $2 \mathrm{~h}$ at $25^{\circ} \mathrm{C}$. Control consisted of replacing the suspension with PBS. HAdV2 DNA was extracted and purified using a high pure viral nucleic acid kit (Roche, Switzerland). Briefly, $200 \mu \mathrm{l}$ of binding buffer supplemented with $50 \mu \mathrm{l}$ proteinase $\mathrm{K}$ and poly(A) (Roche, Switzerland) was added to the treated virus suspension and incubated at $72^{\circ} \mathrm{C}$ for $15 \mathrm{~min}$. The mixture was then added to a high pure filter column and centrifuged three times at $8,000 \mathrm{~g}$ for $1 \mathrm{~min}$, with flow-through being discarded after each centrifugation cycle. The column was then washed twice with $450 \mu \mathrm{l}$ of wash buffer (Roche,
Switzerland). Elution of HAdV2 dsDNA occurred by adding 40 $\mu \mathrm{l}$ of elution buffer and centrifugation at 13,000 $\mathrm{g}$ for $1 \mathrm{~min}$. Viral DNA was stored at $-20^{\circ} \mathrm{C}$ until analysis by electrophoresis. Then $150 \mathrm{ng}$ of purified viral dsDNA was mixed with $5 \mu \mathrm{l}$ of gel loading buffer and loaded on $1.2 \%(\mathrm{w} / \mathrm{v})$ agarose gel in TBE buffer with SYBR Safe DNA gel stain (ThermoFischer, United Kingdom). The lambda DNA/HindIII marker size profile was used.

Purified HAdV2 dsDNA was digested separately by SmaI and AatII restriction enzymes (Thermo Scientific, Germany) in order to evaluate more specifically potential damage to viral nucleic acid caused by formulations (see Table 1 for details). After digestion, electrophoresis was performed on a $2 \%(\mathrm{w} / \mathrm{v})$ agarose gel in TBE buffer at $100 \mathrm{~V}$ for $1 \mathrm{~h}$ and $30 \mathrm{~min}$. Viral dsDNA bands were visualized as described earlier.

\section{Electron Microscopy}

Five $\mu \mathrm{L}$ of a HAdV5/attP preparation containing $1 \times 10^{12}$ viral particles/ml previous dialyzed against HBS during $1 \mathrm{~h}$ at $4^{\circ} \mathrm{C}$. This concentration refers to physical particles. The virus sample was diluted in $\mathrm{HBS}$ with and without $5 \mathrm{mM} \mathrm{NiCl}_{2}$ and incubated on glow discharged collodion/carbon coated grids for $5 \mathrm{~min}$, blotted and incubated with $45 \mu \mathrm{L}$ of formulation for different times and conditions. Grids were washed with HBS $(500 \mu \mathrm{L})$, stained with $2 \%(\mathrm{w} / \mathrm{v})$ uranyl acetate for $30 \mathrm{~s}$ and examined in a JEOL JEM 1,230 transmission electron microscope at $100 \mathrm{kV}$.

\section{Atomic Force Microscopy}

Purified HAdV5/attP previous dialyzed against HBS during $1 \mathrm{~h}$ at $4{ }^{\circ} \mathrm{C}$ was diluted in $\mathrm{HBS}$ with $5 \mathrm{mM} \mathrm{NiCl}_{2}$ to a concentration of $1.5 \times 10^{12}$ viral particles/ml. Twenty microliter of virus suspension were then deposited on freshly cleaved mica and incubated for $20 \mathrm{~min}$ at $4^{\circ} \mathrm{C}$. After washing the sample with

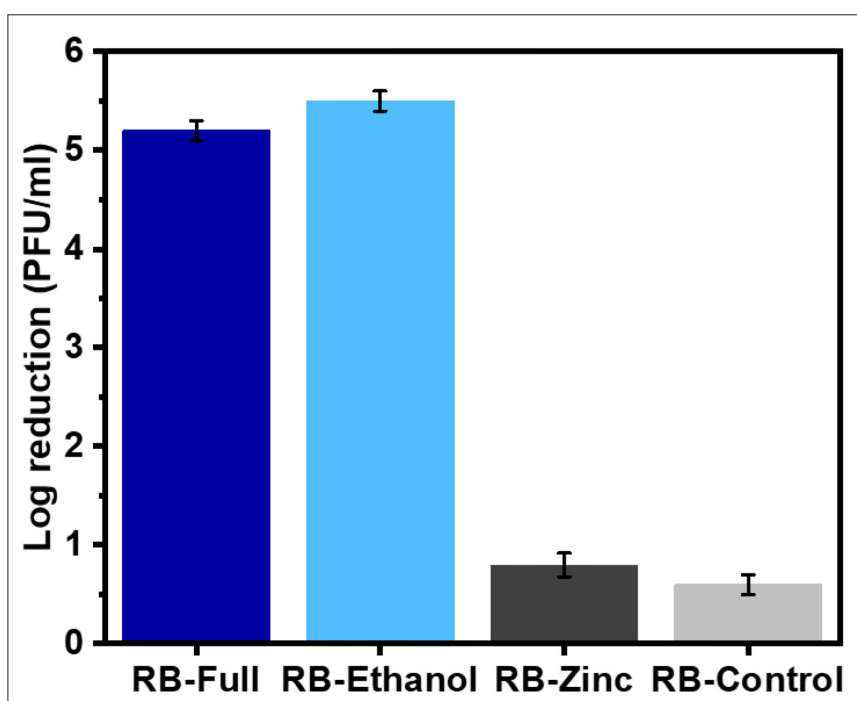

FIGURE 1 | Efficacy of the different formulations against HAdV2 using the EN14776 suspension test. Test conditions: 60 min contact time, hard water, no organic load. 


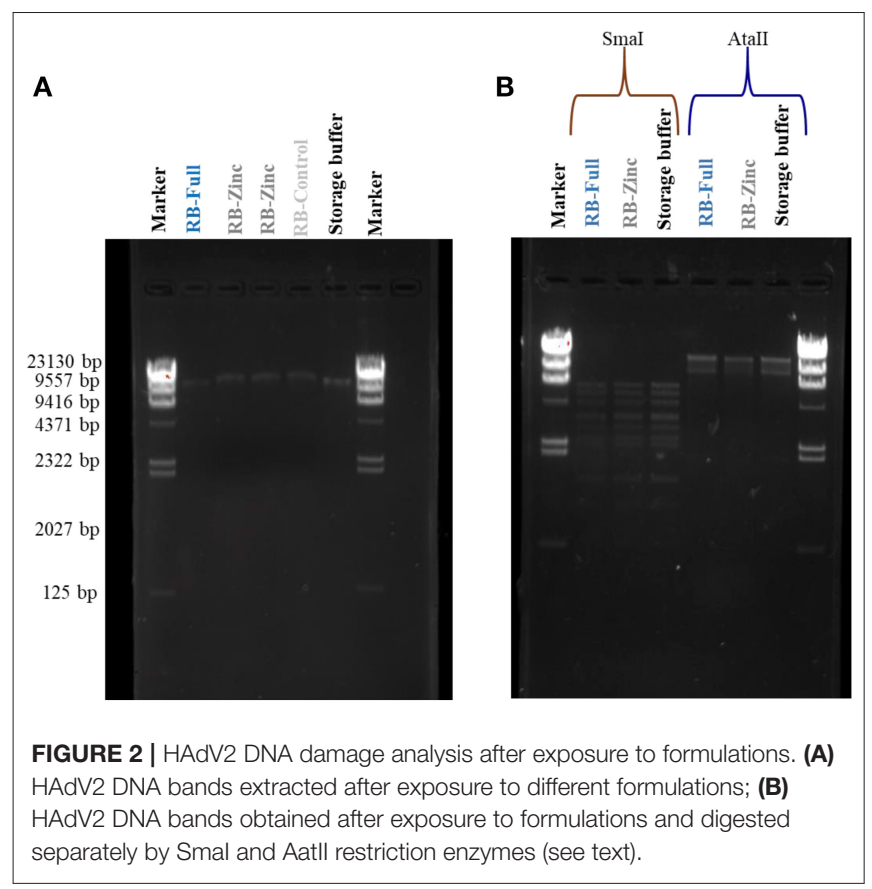

HBS- $5 \mathrm{mM} \mathrm{NiCl}_{2}$ to remove the non-adsorbed particles, $180 \mu \mathrm{l}$ of formulation were added for a set exposure time and then washed again with $\mathrm{HBS}-5 \mathrm{mM} \mathrm{NiCl} 2$ buffer and immersed in 500 $\mu \mathrm{l}$ of $\mathrm{HBS}$ with $5 \mathrm{mM} \mathrm{NiCl}_{2}$ (Supplementary Figure 1). Short exposure times of $0.5,1,2.5,5$, and $10 \mathrm{~min}$ were chosen to verify whether the structural integrity of the majority of the viral particles was maintained or not. Measurements were performed using an AFM (Nanotec Electrónica S.L., Madrid, Spain) operating in jumping plus mode (Ortega-Esteban et al., 2012) in liquid milieu with a force of $70 \mathrm{pN}$. Cantilevers (RC800PSA, Olympus, Tokyo, Japan) with nominal spring constants of 0.05 $\mathrm{N} / \mathrm{m}$ were used and calibrated using Sader's method (Sader et al., 1999). AFM nanoindentation (force vs. z-piezo displacement; FZ) experiments were performed on viral particles to obtain their mechanical properties (Supplementary Figure 3) at a certain incubation time.

\section{RESULTS}

\section{Virucidal Activity of Formulations}

Following the use of the BS EN14476 protocol, the virucidal activity of the different formulations after $60 \mathrm{~min}$ exposure in hard water but with no organic load showed that the full formulation and the formulated ethanol (RB-Full and RBEthanol) (Figure 1) showed a significant reduction in $\mathrm{PFU} / \mathrm{ml}$ compared to the formulated zinc or the control containing excipients only $(p<0.05)$. The formulation control (RB-Control) which contained excipients only did not show any reduction in HAdV2 infectivity and the lack of virus inactivation was comparable to RB-Zinc (Figure 1). Furthermore, there was no difference in activity between RB-Full and RB-Ethanol.
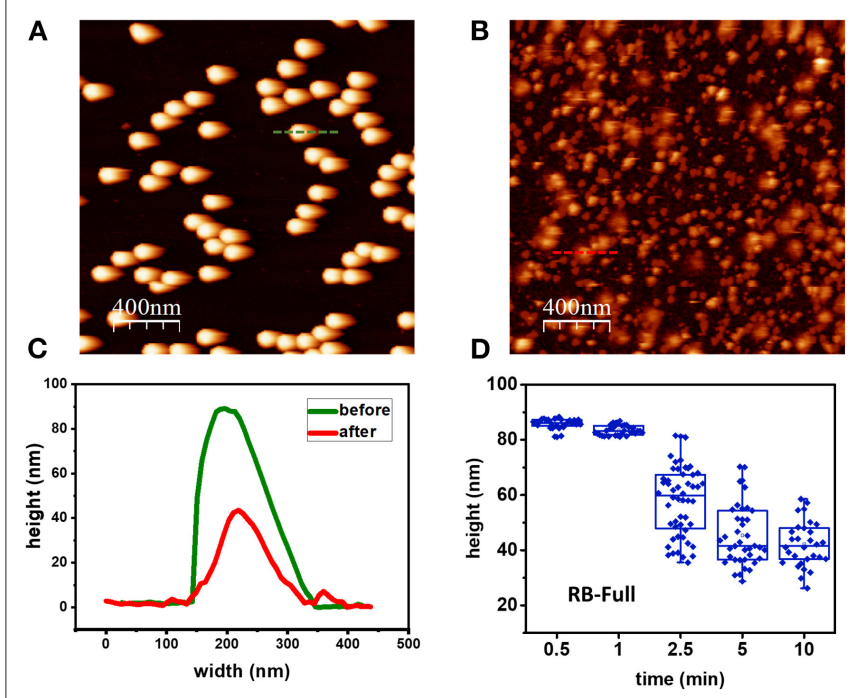

FIGURE 3 | Morphology changes induced by formulation RB-Full. (A) Control: AFM image taken before treatment. (B) AFM image taken after 5 min contact with RB-Full. (C) Profiles of one viral particle and before (green line) and after (red line) treatment with RB-Full. (D) Box plot showing the evolution of particle height as a function of treatment time with RB-Full.

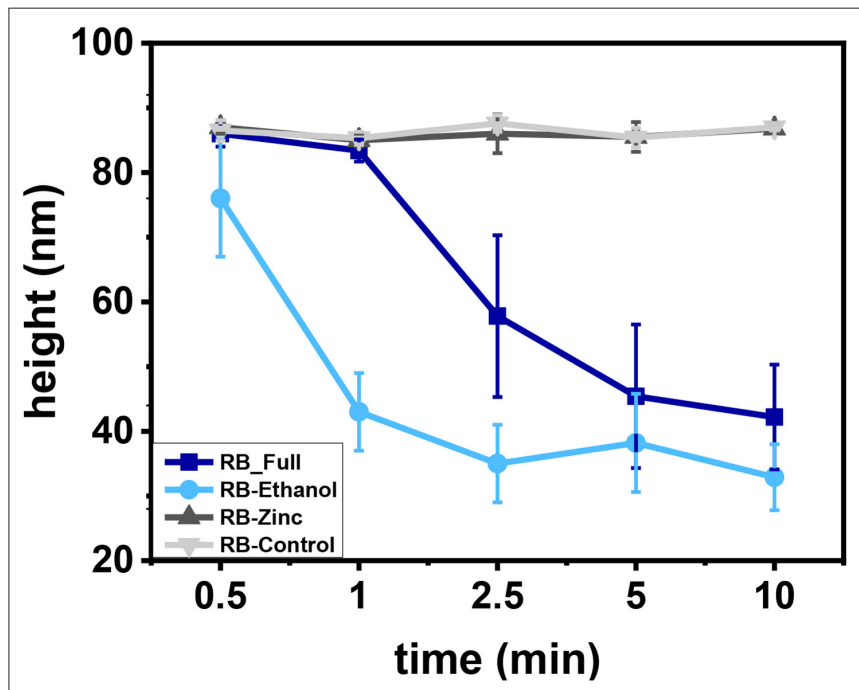

FIGURE 4 | Particle height evolution after treatment with the different formulations as a function of time. Height average values and standard deviation are plotted. The $N=50$ for all the formulations and contact times.

\section{DNA Damage Analysis}

Potential damage to viral DNA was evaluated for HAdV2. There was no apparent DNA damage following virus exposure to any of the formulations. Severe damage associated with random multiple breaks in DNA (Maillard et al., 1995; Elnifro et al., 2000) would take the form of a smear (Figure 2A). In addition, the use of restriction enzymes, which would indicate random DNA breaks, did not show any differences in DNA band pattern following virus exposure to different formulations (Figure 2B). 


\section{Morphological Analysis}

The effect of the different formulations in HAdV particle morphology was analyzed using AFM imaging in liquids and TEM. HAdV5/attP particles were imaged after exposure to the different formulations at various incubation times. Figure 3A shows a typical AFM topography of a random population of HAdV5/attP particles obtained in liquid condition before treatment. The topographical profile of one of the particles, marked by a green line in Figure 3C indicated that the particle size is $86 \mathrm{~nm}$, in agreement with the nominal diameter of a HAdV virion (San Martín, 2012). This revealed that the interaction with the mica surface or AFM imaging did not alter the particle structure. The impact of the different formulations on the particle morphology following different incubation times was then measured. In Figure 3B we showed an example of HAdV5/attP incubation in RB-Full for $5 \mathrm{~min}$, that resulted in drastic morphological alterations. The topographical profile (red line in Figure 3C) demonstrated that the height for the particle taken as an example decreased to $45 \mathrm{~nm}$ (a $50 \%$ reduction for this particular virion). Analysis of a particle height dataset showed decreases with increasing RB-Full exposure time up to 52\% after 10 min (Figure 3D), indicative of capsid disruption or collapse. Moreover, RB-Ethanol significantly induced morphological changes in HAdV5/attP (Figure 4 and Supplementary Figure 2). This is supported by a decreasing of the height with increasing incubation time. RB-Full decreased the height of the particle by $52 \%$ after $5 \mathrm{~min}$ of exposure time, whilst RB-ethanol decreased virus particle height by $62 \%$ after 2.5 min (Figure 4). RB-Zinc and RB-Control did not produce any height reduction in viral particles, regardless of the exposure time
(Figure 4). RB-Full which contains both ethanol and zinc seemed to have a lesser effect on the integrity of the viral particles causing less damage when compared to the formulation containing only ethanol (RB-Ethanol).

On the other hand, TEM images only revealed damage when treated with RB-Ethanol after 5 min of incubation (Figure 5). The other formulations did not reveal any gross morphological changes in HAdV5/attP particles independently of the contact time when only HBS was present (Figure 5). The apparent discrepancy between the AFM and TEM results with RBFull formulation may originate from the differences in the experimental setup between the two imaging techniques. In particular, AFM imaging of HAdV particles adsorbed to mica requires the presence of $\mathrm{Ni}^{+2}$ ions in the buffer (Ortega-Esteban et al., 2013). We hypothesized the possibility of a synergistic effect between RB-Full and nickel salt used for the AFM assays. To verify this hypothesis, we repeated the TEM experiments adding $\mathrm{Ni}_{2} \mathrm{Cl}$ to the HBS buffer at the same concentration used in the AFM protocol. This addition showed some damaged viral particles after $5 \mathrm{~min}$ of incubation by TEM (Figure 5 and Supplementary Figure 2), which still do not suffice to provide the average height showed in AFM (Figure 4, dark blue). The excess of disrupted particles found in AFM can be ascribed to the fact that virus specimens are typically subjected to forces of $\sim 100 \mathrm{pN}$ during imaging. It is known that such low force can disrupt previously weakened virus structures (Ortega-Esteban et al., 2015). In the present case, it is likely that virus particles are deteriorated by the combination of RB-Full and $\mathrm{NiCl}_{2}$ and destroyed during AFM imaging. Therefore, a combination of

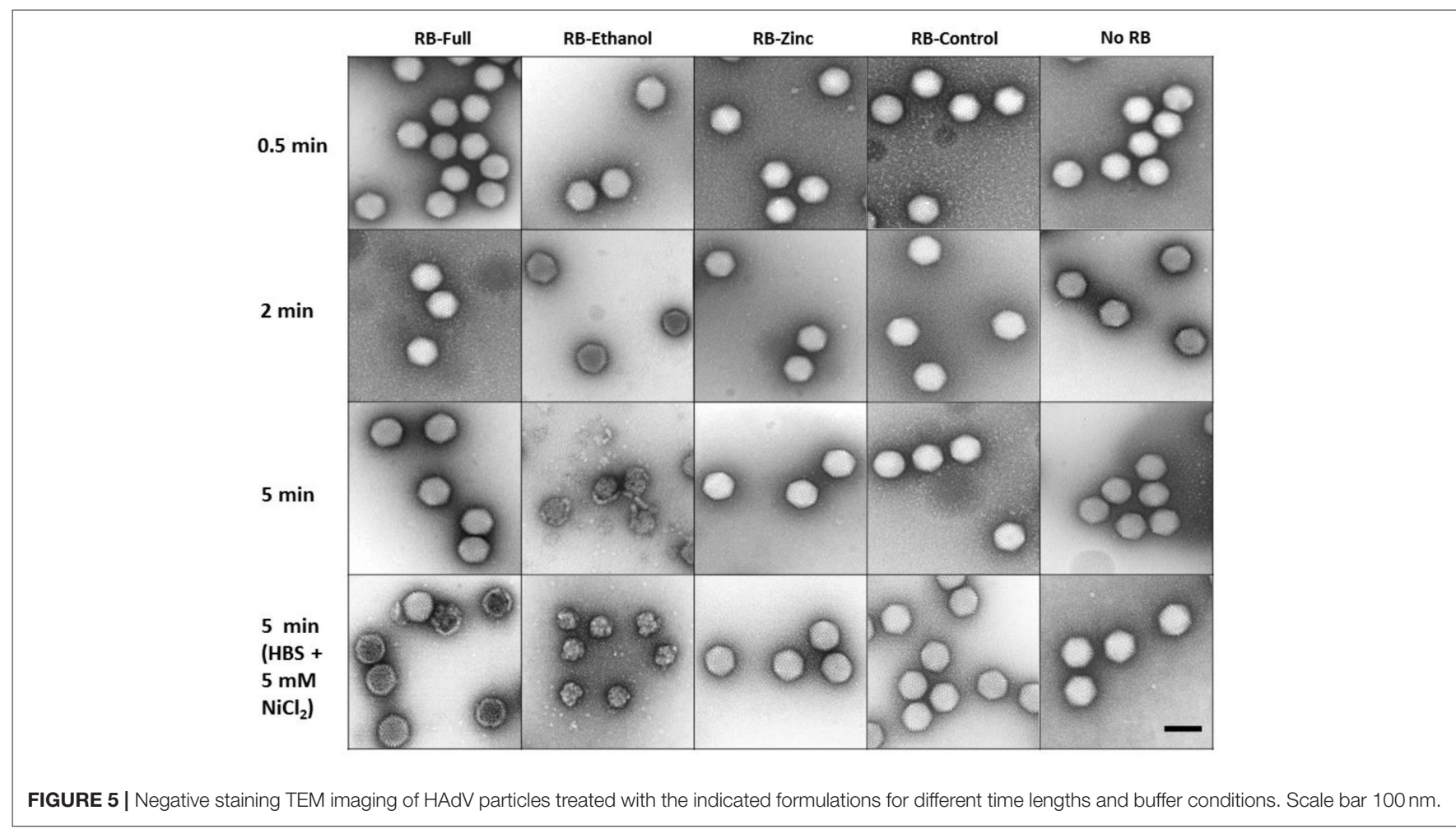




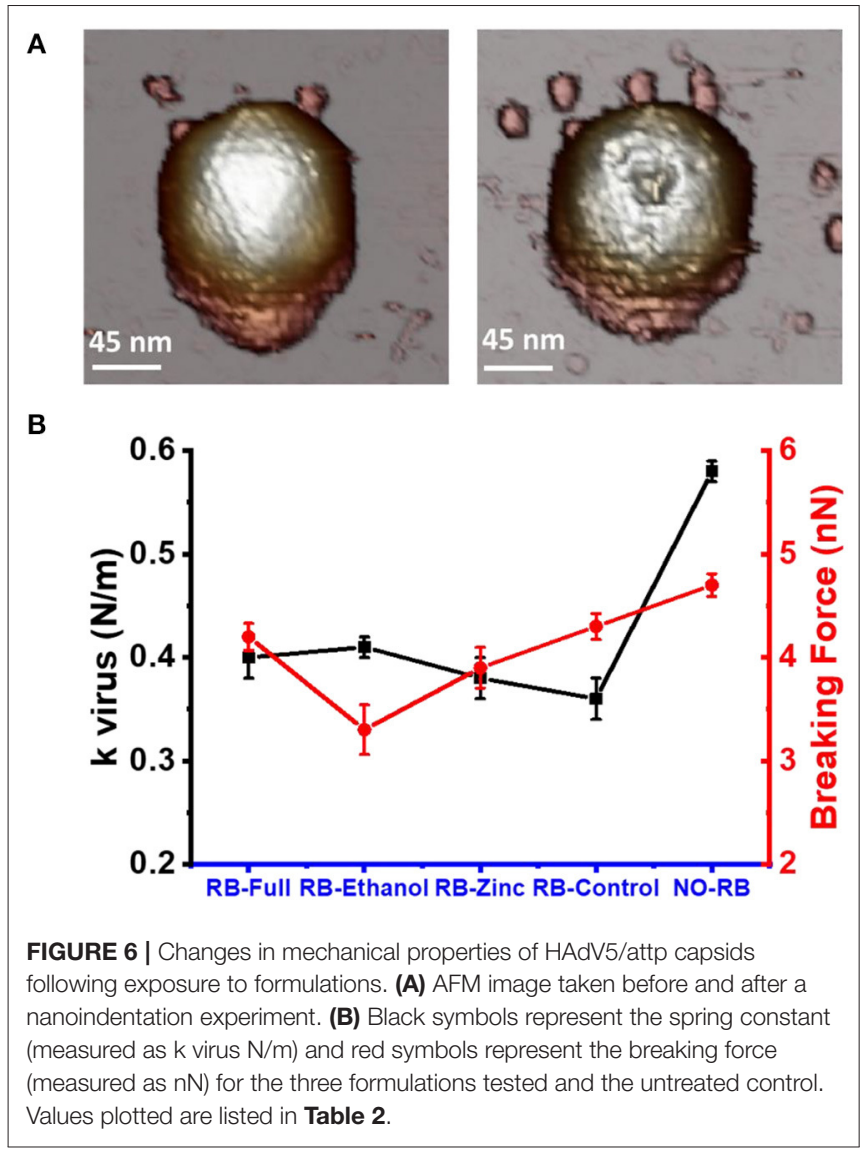

RB-Full with $5 \mathrm{mM} \mathrm{NiCl}_{2}$ is responsible for the structural damage observed using both AFM and TEM.

\section{Mechanical Properties}

Changes in the mechanical properties of the HAdV5/attP virions were measured as stiffness (spring constant) and breaking force (Supplementary Figure 3). An incubation time of $0.5 \mathrm{~min}$ with the formulations diluted 1:1 in Milli-Q $\mathrm{H}_{2} \mathrm{O}$ was chosen to have structurally intact viral particles that can be analyzed mechanically. Using this contact time, we ensured there was no reduction in height of $\mathrm{HAdV}$-5/attP caused by the formulation. Intact viral particles exhibited a linear behavior until the elastic limit was reached breaking the particle (Figure 6A). The particle spring constant was significantly (ANOVA, $p<0.05$ ) lower in samples exposed to the formulations when compared to untreated control, showing that particles became softer when incubated with the formulations (Table 2 and Figure 6B). However, no significant variation was found between the effect of the four formulations, as indicated by a Kolmoworov-Smirnov test of the measurements. This observation indicates that the excipients and highly basic $\mathrm{pH}$ present in all formulations tested alter HAdV particle stiffness. In contrast, exposure of HAdV5/attP to RB-Ethanol significantly decreased the breaking force indicating a weakening of the viral capsid when comparing with the other formulations. The maximum required force to break the particle is decreased in this case showing that the viral
TABLE 2 | Mechanical properties of HAdV5/attP particles after treatment with the indicated formulations for $0.5 \mathrm{~min}$.

\begin{tabular}{lccc}
\hline Formulation & Spring constant (N/m) & Breaking Force (nN) & N \\
\hline RB-Full & $0.40 \pm 0.02$ & $4.2 \pm 0.1$ & 38 \\
RB-Ethanol & $0.41 \pm 0.02$ & $3.3 \pm 0.2$ & 36 \\
RB-Zinc & $0.38 \pm 0.02$ & $4.0 \pm 0.2$ & 37 \\
RB-Control & $0.36 \pm 0.02$ & $4.3 \pm 0.1$ & 31 \\
NO RB & $0.58 \pm 0.01$ & $4.7 \pm 0.1$ & 100
\end{tabular}

$N$, number of virions observed.

particles are more brittle (i.e., for the same deformation the force to break the particle is lower).

\section{DISCUSSION}

Biocidal products play an important role for the control or elimination of microbial contamination in a wide range of settings. Some microorganisms, and notably non-enveloped viruses are more challenging to inactivate than enveloped ones due to the lack of a lipid bilayer envelope as a potential target (Ijaz and Rubino, 2008). The development of synergistic formulations based on combining active ingredients or/and selecting appropriate formulation excipients is important as this can lead to significant increase in disinfection efficacy while reducing toxicity and improving surface compatibility. Overall, there is little understanding of the mechanisms underlying virucidal activity of alcohol and metal ions in a given formulation. In this study, we aimed to produce a better insight of the use of zinc salt to potentiate the virucidal activity of a ethanol formulation against a non-enveloped virus. In our experimental set up we decided to use ethanol and the different control in a formulation as this would represent better the use of a final disinfectant product. Besides the impact of a formulation on biocidal activity is rarely investigated, hindering the application of findings to the efficacy of a final product in practice.

The RB-Full $[0 \%(\mathrm{w} / \mathrm{v})$ ethanol $+0.1 \%(\mathrm{w} / \mathrm{v})$ zinc salt; $\mathrm{pH}$ 10.5] and the RB-Ethanol [40\% (w/v) ethanol + excipients; $\mathrm{pH}$ 10.5] formulations were virucidal against HAdV2 ( $>5 \log _{10}$ reduction) within $60 \mathrm{~min}$ at room temperature and without organic load. RB-Zinc [0.1\% (w/v) zinc sulfate + excipients; $\mathrm{pH}$ 10.5] on the control (excipients only) were not. Unformulated ethanol is considered to have a rapid virucidal activity (within $2 \mathrm{~min}$ ) against adenovirus type 2 at concentrations between 55 and 85\%. For adenovirus type 5, the reported effective concentration of unformulated ethanol ranges between 45 and 95\% (Kampf, 2018). No gross structural damage of the virions was observed by TEM using RB-Full which contrasted with the damaging effect of RB-Ethanol. Although TEM observations cannot be directly correlated to the level virucidal activity, the mechanisms of virions inactivation between the 2 formulations could be different, since both RB-Full and RB-Ethanol showed the same virucidal efficacy. These findings also questioned the role of zinc in the full formulation. We originally hypothesize that sufficient damage to the viral capsid imparted, for example, by ethanol would allow zinc penetration and its interaction with 
viral DNA. Zinc has been shown to interact directly with dsDNA (Evilevitch et al., 2011). Free zinc ions $\left(\mathrm{Zn}^{2+}\right)$ have been shown to be able to bind to DNA and change its secondary structure mainly through interactions with DNA phosphate sugar backbone as well as guanine and cytosine (Aich et al., 1999). A high ratio of $\mathrm{Zn}^{2+}$ to DNA has also been shown to destabilize the DNA double helix decreasing its melting temperatures (Souza et al., 2000; Labiuk et al., 2003). In addition, the viral genome can impact on capsid mechanics (Labiuk et al., 2001; Ivanovska et al., 2007). However, we did not observe that zinc caused any damage to viral dsDNA.

Although no major structural damage of the virions was observed by TEM using RB-Full, the addition of $\mathrm{Ni}^{2+}$ produced gross alterations of the viral particles. Such gross damage was confirmed with AFM suggesting capsid weakening with increased incubation time. We hypothesize that $\mathrm{NiCl}_{2}$ was necessary to observe gross viral particle alteration when combined to the RB-Full formulation. The use of $\mathrm{NiCl}_{2}$ in the AFM protocol was necessary because divalent ions are required for virus adsorption on mica. The potential mechanistic synergistic effect combining the RB-Full formulation with $\mathrm{NiCl}_{2}$ was not expected and opens an interesting avenue for further formulation optimization. The mechanical properties of the viral capsid such as stiffness and capacity to withstand pressure such as DNA packing and cell entry process, and extracellular conditions including osmotic pressure, desiccation and $\mathrm{pH}$, plays a significant role for their viability (Carrasco et al., 2011; Greber, 2016). Research on the mechanical properties of adenovirus exposed to the full formulation in the presence of $\mathrm{NiCl}_{2}$ resulted in a reduction of the capsid rigidity. The observed lower breaking force in this study indicates that the virus would be more susceptible to environment chemical and mechanical stress (Hernando-Pérez et al., 2014). RB-Ethanol with $\mathrm{NiCl}_{2}$ affected the ability of the virus to withstand pressure rather than its stiffness, ultimately decreasing the viral capsid ability to withstand mechanical stress (Hernando-Pérez et al., 2014). The mechanical properties of the virions were measured on intact particles in order to avoid the influence of structural defects (cracks, vacancies, etc.). In this way, we were able to identify subtle changes on the capsomer bonds induced by the formulations. From our data (Figure 6) differences in the mechanical alterations of viruses between formulations were not extensive. However, we observed that all the formulations tested produced changes in the virus mechanics which contrasts with untreated viruses (Figure 6B).

Although it is tempting to explain virucidal activity with the observed damage to the viral particles, there is no direct correlation between gross viral particle alteration and infectivity assays.

\section{CONCLUSION}

The need for biocidal product manufacturers to decrease alcohol concentration for environmental, regulatory and commercial reasons, while maintaining virucidal activity is challenging. We hypothesized that the addition of zinc might potentiate a low (non virucidal) concentration of ethanol (here $40 \%$ ). We combined different techniques to investigate the interplay between the infectivity, integrity and mechanical effects of ethanol and zinc salt as active ingredients against HAdV. We observed that HAdV particles were inactivated (5 $\log _{10}$ reduction in $\mathrm{PFU} / \mathrm{ml}$ ) when exposed to the $\mathrm{RB}$-full and $\mathrm{RB}$ Ethanol for $60 \mathrm{~min}$ in clean conditions, although only the formulated ethanol produced gross morphological change to the viral particles after $5 \mathrm{~min}$ exposure. It was interesting to observe that the presence of $5 \mathrm{mM} \mathrm{NiCl} 2$ contributed to the structural damage imparted by the full formulation. AFM confirmed that capsid topography reduced considerable when virus was exposed to the full formulation in te presence of $\mathrm{NiCl}_{2}$. Although the addition of zinc did not seem to improve the efficacy of the formulation, the addition of $\mathrm{NiCl}_{2}$ contributing to a weakening of the viral capsid offers an interesting avenue to pursue.

The use of AFM was instrumental in making such observations and as such, AFM has shown to be an important tool for understanding the mechanistic impact of virucidal formulation.

\section{DATA AVAILABILITY STATEMENT}

The original contributions presented in the study are included in the article/Supplementary Material, further inquiries can be directed to the corresponding author/s.

\section{AUTHOR CONTRIBUTIONS}

NM-G and LV peformed AFM and virucide experiments, respectivelly, and wrote the paper. GNC peformed TEM experiments. MR, IF, JR, and MI prepared virucides. CSM, J-YM, and PD designed research and wrote the paper. All authors contributed to the article and approved the submitted version.

\section{FUNDING}

Reckitt Benckiser funded a PhD Studentship (LV) administered by Cardiff University. CSM and GNC were supported by grants PID2019-104098GB-I00/AEI/10.13039/501100011033 and BFU2016-74868-P, co-funded by the Spanish State Research Agency and the European Regional Development Fund, as well as BFU2013-41249-P and BIO2015-68990-REDT (the Spanish Adenovirus Network, AdenoNet) from the Spanish Ministry of Economy, Industry and Competitiveness; and the Agencia Estatal CSIC (2019AEP045). The CNB-CSIC was further supported by a Severo Ochoa Excellence grant (SEV 2017-0712). PJP acknowledges grants from the Spanish Ministry of Economy, Industry and Competitiveness projects (FIS2017- 89549-R; Maria de Maeztu Program for Units of Excellence in R\&D MDM-20140377; and FIS2017-90701- REDT) and Human Frontiers Science Program (HFSPO RGP0012/2018).

\section{SUPPLEMENTARY MATERIAL}

The Supplementary Material for this article can be found online at: https://www.frontiersin.org/articles/10.3389/fmolb. 2020.570914/full\#supplementary-material 


\section{REFERENCES}

Aich, P., Labiuk, S. L., Tari, L. W., Delbaere, L. J., Roesler, W. J., Falk, K. J., et al. (1999). M-DNA: A complex between divalent metal ions and DNA which behaves as a molecular wire. J. Mol. Biol. 294, 477-485. doi: 10.1006/jmbi.1999.3234

Alba, R., Hearing, P., Bosch, A., and Chillon, M. (2007). Differential amplification of adenovirus vectors by flanking the packaging signal with attB/attP- $\Phi \mathrm{C} 31$ sequences: implications for helper-dependent adenovirus production. Virology 367, 51-58. doi: 10.1016/j.virol.2007. 05.014

Alhmidi, H., Koganti, S., Cadnum, J. L., Jencson, A. L., John, A., and Donskey, C. J. (2017). Dissemination of a nonpathogenic viral DNA surrogate marker from high-touch surfaces in rooms of long-term care facility residents. Am. J. Infect. Control 45, 1165-1167. doi: 10.1016/j.ajic.2017. 04.007

BS EN 14476:2013+A2:2019. Chemical Disinfectants and Antiseptics. Quantitative Suspension Test for the Evaluation of Virucidal Activity in the Medical Area. Test Method and Requirements (Phase 2/Step 1). London: British Standard Institute.

Carrasco, C., Luque, A., Hernando-Pérez, M., Miranda, R., Carrascosa, J. L., Serena, P. A., et al. (2011). Built-in mechanical stress in viral shells. Biophys. J. 100, 1100-1108. doi: 10.1016/j.bpj.2011. 01.008

Condell, O., Iversen, C., Cooney, S., Power, K. A., Walsh, C., Burgess, C., et al. (2012). Efficacy of biocides used in the modern food industry to control salmonella enterica, and links between biocide tolerance and resistance to clinically relevant antimicrobial compounds. Appl. Environ. Microbiol. 78, 3087-3097. doi: 10.1128/AEM.07534-11

Condezo, G. N., Marabini, R., Ayora, S., Carazo, J. M., Alba, R., Chillón, M., et al. (2015). Structures of adenovirus incomplete particles clarify capsid architecture and show maturation changes of packaging protein L1 52/55k. J. Virol. 89, 9653-9664. doi: 10.1128/JVI.01453-15

Elnifro, E. M., Cooper, R. J., Klapper, P. E., and Bailey, A. S. (2000). PCR and restriction endonuclease analysis for rapid identification of human adenovirus subgenera. J. Clin Microbiol. 38:7. doi: 10.1128/JCM.38.6.2055-20 61.2000

Evilevitch, A., Roos, W. H., Ivanovska, I. L., Jeembaeva, M., Jönsson, B., and Wuite, G. J. L. (2011). Effects of salts on internal DNA pressure and mechanical properties of phage capsids. J. Mol. Biol. 405, 18-23. doi: 10.1016/j.jmb.2010. 10.039

Flint, S. J., and American Society for Microbiology (2009). Principles of Virology. Washington, DC: ASM Press. Available online at: http:// public.eblib.com/choice/publicfullrecord.aspx? $\mathrm{p}=605163 \quad$ (accessed April 28, 2020).

Gaonkar, T. A., Geraldo, I., Shintre, M., and Modak, S. M. (2006). In vivo efficacy of an alcohol-based surgical hand disinfectant containing a synergistic combination of ethylhexylglycerin and preservatives. J. Hosp. Infect. 63, 412-417. doi: 10.1016/j.jhin.2006. 03.005

Gonçalves, K. J., Graziano, K. U., and Kawagoe, J. Y. (2012). Revisão sistemática sobre antissepsia cirúrgica das mãos com preparação alcoólica em comparação aos produtos tradicionais. Rev. Esc. Enferm. USP 46, 1484-1493. doi: 10.1590/S0080-62342012000600028

Greber, U. F. (2016). Virus and host mechanics support membrane penetration and cell entry. J. Virol. 90, 3802-3805. doi: 10.1128/JVI.02 $568-15$

Guthery, E., Seal, L. A., and Anderson, E. L. (2005). Zinc pyrithione in alcohol-based products for skin antisepsis: persistence of antimicrobial effects. Am. J. Infect. Control 33, 15-22. doi: 10.1016/j.ajic.2004. 07.012

Hernando-Pérez, M., Pascual, E., Aznar, M., Ionel, A., Castón, J. R., Luque, A., et al. (2014). The interplay between mechanics and stability of viral cages. Nanoscale 6, 2702-2709. doi: 10.1039/C3NR0 $5763 \mathrm{~A}$

Ijaz, M. K., and Rubino, J. (2008). Should test methods for disinfectants use vertebrate viruses dried on carriers to advance virucidal claims? Infect. Control Hosp. Epidemiol. 29, 192-194. doi: 10.1086/ 526441

Ivanovska, I., Wuite, G., Jönsson, B., and Evilevitch, A. (2007). Internal DNA pressure modifies stability of WT phage. Proc. Natl. Acad. Sci. U. S. A. 104, 9603-9608. doi: 10.1073/pnas.0703166104

Kampf, G. (2018). Efficacy of ethanol against viruses in hand disinfection. J. Hosp. Infect. 98, 331-338. doi: 10.1016/j.jhin.2017. 08.025

Kramer, A., Galabov, A. S., Sattar, S. A., Döhner, L., Pivert, A., Payan, C., et al. (2006). Virucidal activity of a new hand disinfectant with reduced ethanol content: comparison with other alcohol-based formulations. J. Hosp. Infect. 62, 98-106. doi: 10.1016/j.jhin.2005.06.020

Labiuk, S. L., Delbaere, L. T., and Lee, J. S. (2001). Gamma and ultraviolet radiation cause DNA crosslinking in the presence of metal ions at high $\mathrm{pH}$. Photochem. Photobiol. 73, 579-584. doi: 10.1562/0031-8655(2001)073<0579:GAURCD>2.0.CO;2

Labiuk, S. L., Delbaere, L. T. J., and Lee, J. S. (2003). Cobalt(II), nickel(II) and zinc(II) do not bind to intra-helical $\mathrm{N}$ (7) guanine positions in the Bform crystal structure of d(GGCGCC). JBIC J. Biol. Inorg. Chem. 8, 715-720. doi: 10.1007/s00775-003-0473-4

Macinga, D. R., Sattar, S. A., Jaykus, L.-A., and Arbogast, J. W. (2008). Improved inactivation of nonenveloped enteric viruses and their surrogates by a novel alcohol-based hand sanitizer. Appl. Environ. Microbiol. 74, 5047-5052. doi: 10.1128/AEM.00487-08

Maillard, J.-Y. (2001). Virus susceptibility to biocides: an understanding: Rev. Med. Microbiol. 12, 63-74. doi: 10.1097/00013542-20010400000001

Maillard, J.-Y., Beggs, T. S., Day, M. J., Hudson, R. A., and Russell, A. D. (1995). Effects of biocides on the transduction of Pseudomonas aeruginosa PAO by F116 bacteriophage. Lett. Appl. Microbiol. 21, 215-218. doi: 10.1111/j.1472-765X.1995.tb 01044.x

Mcdonnell, G., and Russell, A. D. (1999). Antiseptics and disinfectants: activity, action, and resistance. Clin Microbiol Rev. 12:33. doi: 10.1128/CMR. 12.1.147

Myers, F. (2008). Biocidal agents: modes of action and correlation with antibiotic resistance. Biomed. Sci, 52, 227-231.

Ortega-Esteban, A., Condezo, G. N., Pérez-Berná, A. J., Chillón, M., Flint, S. J., Reguera, D., et al. (2015). Mechanics of viral chromatin reveals the pressurization of human adenovirus. ACS Nano 9, 10826-10833. doi: 10.1021/acsnano.5b03417

Ortega-Esteban, A., Horcas, I., Hernando-Pérez, M., Ares, P., Pérez-Berná, A. J., San Martín, C., et al. (2012). Minimizing tip-sample forces in jumping mode atomic force microscopy in liquid. Ultramicroscopy 114, 56-61. doi: 10.1016/j.ultramic.2012.01.007

Ortega-Esteban, A., Pérez-Berná, A. J., Menéndez-Conejero, R., Flint, S. J., Martín, C. S., and de Pablo, P. J. (2013). Monitoring dynamics of human adenovirus disassembly induced by mechanical fatigue. Sci. Rep. 3:1434. doi: 10.1038/srep01434

Rajasekaran, P., Kannan, H., Das, S., Young, M., Santra, S. (2016). Comparative analysis of copper and zinc based agrichemical biocide products: materials characteristics, phytotoxicity and in vitro antimicrobial efficacy. AIMS Environ. Sci. 3, 439-455. doi: 10.3934/environsci.20 16.3.439

Russell, A. (2003). Biocide use and antibiotic resistance: the relevance of laboratory findings to clinical and environmental situations. Lancet Infect. Dis. 3, 794-803. doi: 10.1016/S1473-3099(03)00833-8

Rutala, W. A., and Weber, D. J. (2014). Selection of the ideal disinfectant. Infect. Control Hosp. Epidemiol. 35, 855-865. doi: 10.1086/ 676877

Sader, J. E., Chon, J. W. M., and Mulvaney, P. (1999). Calibration of rectangular atomic force microscope cantilevers. Rev. Sci. Instrum. 70, 3967-3969. doi: $10.1063 / 1.1150021$

San Martín, C. (2012). Latest insights on adenovirus structure and assembly. Viruses 4, 847-877. doi: 10.3390/v4050847

Souza, J. R., de, Castro, C. S. P., de, and Bloch, C. Jr. (2000). Zinc binding to lambda phage DNA studied by voltammetric techniques. 
J. Braz. Chem. Soc. 11, 398-404. doi: 10.1590/S0103-505320000 00400013

Suchomel, M., Gnant, G., Weinlich, M., and Rotter, M. (2009). Surgical hand disinfection using alcohol: the effects of alcohol type, mode and duration of application. J. Hosp. Infect. 71, 228-233. doi: 10.1016/j.jhin.2008. 11.006

van Engelenburg, F. A. C., Terpstra, F. G., Schuitemaker, H., and Moorer, W. R. (2002). The virucidal spectrum of a high concentration alcohol mixture. J. Hosp. Infect. 51, 121-125. doi: 10.1053/jhin.200 2.1211

Ytreberg, E., Karlsson, J., and Eklund, B. (2010). Comparison of toxicity and release rates of $\mathrm{Cu}$ and $\mathrm{Zn}$ from anti-fouling paints leached in natural and artificial brackish seawater. Sci. Total Environ. 408, 2459-2466. doi: 10.1016/j.scitotenv.2010. 02.036
Conflict of Interest: JR and MI are employed by the company Reckitt Benckiser Inc.

The remaining authors declare that the research was conducted in the absence of any commercial or financial relationships that could be construed as a potential conflict of interest.

Copyright (c) 2020 Martín-González, Vieira Gonçalves, Condezo, San Martín, Rubiano, Fallis, Rubino, Ijaz, Maillard and De Pablo. This is an open-access article distributed under the terms of the Creative Commons Attribution License (CC BY). The use, distribution or reproduction in other forums is permitted, provided the original author(s) and the copyright owner(s) are credited and that the original publication in this journal is cited, in accordance with accepted academic practice. No use, distribution or reproduction is permitted which does not comply with these terms. 